\title{
A Study on Design of an Operation Simulation System for Technological and Innovative Manufacturing Enterprises
}

\author{
Shijun Tang ${ }^{1}$ and Bingxue Chen ${ }^{2}$ \\ ${ }^{1}$ City College of Wuhan University of Science and Technology, China \\ ${ }^{2}$ Wuhan University of Technology, China
}

\begin{abstract}
As an experiential teaching mode, business operation simulation sandbox-based training plays an important role of "entrepreneurial simulation" teaching in cultivating innovative and entrepreneurial talents. However, mainstream electronic business management simulation sandboxes in China have lagged behind in "simulation" of "innovation" and "entrepreneurship" from design philosophy to application. The current situation is that innovation and entrepreneurship simulation teaching in colleges of China is facing huge pressure of revolution.
\end{abstract}

Keywords-technological innovation; sand-table teaching; simulation of operation

entrepreneurship;

\section{INTRODUCTION}

Today, business operation simulation sandbox-based training has become a popular business management training course in the economic management specialty in colleges of China. [1] As an experiential teaching mode, it integrates theories with practices and role play with post experience. In this mode, students can convert knowledge into skills during participation and experience. Therefore, the teaching mode plays an indispensable role in cultivation of innovative and entrepreneurial talents.

\section{BUSINESS OPERATION AND MANAGEMENT SIMULATION SANDBOX \& EDUCATION IN INNOVATION AND ENTREPRENEURSHIP}

Education in innovation and entrepreneurship can be classified into "entrepreneurship theory teaching", "entrepreneurship simulation", and "innovation and entrepreneurship practice". In business operation simulation sandbox-based training, an experiential teaching mode, students play "managers" through a (physical or electronic) business sandbox, simulating business operation through role play in managerial positions. Therefore, business operation simulation sandbox-based training can perfectly cater to "innovation and entrepreneurship simulation", playing an irreplaceable role in cultivation of innovative and entrepreneurial talents in China both currently and in the future. However, facing the fourth innovation and entrepreneurship wave of "mass entrepreneurship and innovation", education in innovation and entrepreneurship, particularly innovation and entrepreneurship simulation training meets new challenges.

On the one hand, the existing electronic simulation sandboxes can no longer keep up with the Internet+ era that features high-speed innovation. In the contemporary business society driven by technological innovation-based enterprises, traditional teaching sandboxes that simulate only traditional manufacturing enterprises have become inadequate for "simulation" of "innovation".

On the other hand, electronic university innovation and entrepreneurship simulation training platform software that is used for cultivating innovative and entrepreneurial talents in institutions of higher learning, keeps up with the Internet+ era, and focuses on technological innovation-based enterprises can not only provide new curriculum programs for college education in innovation and entrepreneurship in the new era but also promote cultivation of top innovative and entrepreneurial talents for social and economic development in China.

\section{LIMITATIONS OF MAINSTREAM ELECTRONIC BUSINESS OPERATION SIMULATION SANDBOXES IN CHINA}

In today's world, people increasingly emphasize innovation and communication. As traditional business operation simulation sandboxes are based on business competition philosophies of the 1970s and 1980s, more and more limitations of thought and technology are revealed in the face of new demands of current education in innovation and entrepreneurship.

\section{A. "Solidity" of Demands for Innovation}

When simulating demands of an open-source market, traditional business operation simulation sandboxes usually "center consumer demands", which solidifies market preference and demand structure and thereby objectively solidifies business operation and development ideas. Therefore, students cannot "jump out of" the preset market demand structure during the simulation and therefore cannot creatively develop new products or create new market demands.

In the 21st century, with the launch of epochal iPhone, the traditional "consumer demand-centered" product R\&D idea has been rewritten. More and more technological innovation-based enterprises represented by Apple Inc. "create demands" or actively "shape consumer demands" through technological innovation and "hunger marketing". Therefore, in this information age, a new business operation simulation sandbox should also "reflect" the new product design and marketing idea and embrace the principle of "creating 
consumer demands".

\section{B. Operation Simulation Reduce to "Decision"}

Actually, with restriction of course duration and technology, students can experience only "simplistic" business operation during training through traditional business operation simulation sandboxes. In these simulations, "decision making" weighs much more than "practice" of information management systems. Therefore, training through traditional business operation simulation sandboxes usually feels like a "game". Although students "play" hard, they still lack fundamentala cognition of real and mainstream information management systems after the simulation training, which reflects an obvious disadvantage. Therefore, with more and more importance attached to "virtual reality" and efficiency of talent cultivation, we should organically integrate the new business operation simulation sandbox into mainstream job training for information management systems and turn them into the first part of cultivating application capabilities (namely practice capabilities) of business management talents so as to achieve the objective of "moving enterprises in schools".

\section{Isolated Communication}

Mainstream business operation simulation systems in China have the disadvantage of isolated communication. The system is usually installed (with a USB KEY) in the server of the central computer room, and terminal (student) computers in the laboratory remotely access the central server. This, to a large extent, limits time and space of innovation and entrepreneurship simulation teaching because students cannot learn themselves out of class, outside the laboratory, or when they are not authorized by teachers to access the central server. In this way, the strong demand of students for innovation and entrepreneurship is "isolated" from innovation and entrepreneurship teaching. Therefore, we should apply cloud technologies to the new electronic innovation and entrepreneurship simulation sandbox to break such isolation and make terminals for innovation and entrepreneurship simulation teaching applicable both in and out of class so that students can participate in the simulation anytime through information terminals such as desktops, laptops, tablets, and even mobile phones.

\section{DESIGN INNOVATION IN THE NEW SimUlation SANDBOX}

To overcome the obvious disadvantages of mainstream electronic business operation simulation sandboxes in China, we build a new electronic innovation and entrepreneurship sandbox that focuses on technological innovation-based manufacturing enterprises and name it "Entrepreneur Philosophy".

The sandbox simulates business operation and management, offers students several virtual companies and managerial positions (General Manager, Finance Department, Market Department, R\&D Department, Production Department, Sales Department, and HR Department), and creates competition environments of machinery manufacturing, agricultural food processing, IT electronics, and apparel industries so that students can compete and develop in industrial environments selected by teachers. [2] Different from traditional business operation simulation sandboxes, this model features the following design innovations.

\section{A. Embracing the Philosophy of "Creating Market Demands"}

Today, emerging innovative technologies raise great concern with high uncertainty and "creative destruction" of industries. The development of emerging technologies always relies on market growth of emerging products. For example, by launching epochal iPhone, Apple Inc. becomes the leader of the smart phone era. Apple's innovative business model is fundamentally different from the differentiation strategy of other hi-tech companies only pursuing technological leadership. Actually, Apple Inc. initiates a new competition mode of "creating market demands". Therefore, instead of following the "consumer demand-centered" R\&D idea applied to traditional sandboxes, we emphasize "creating market demands" through technological innovation when developing "Entrepreneur Philosophy". For that purpose, we add "awards for launch of innovative products" to the design.

\section{B. Simulating mainstream ERP Software, Valuing Decisions and Reflecting the Management Process}

First, "Entrepreneur Philosophy" has a complete business management process and is similar to a mini ERP information system. It fully integrates management of $R \& D$, marketing, production, finance, and human resources, as shown in Figure I. 


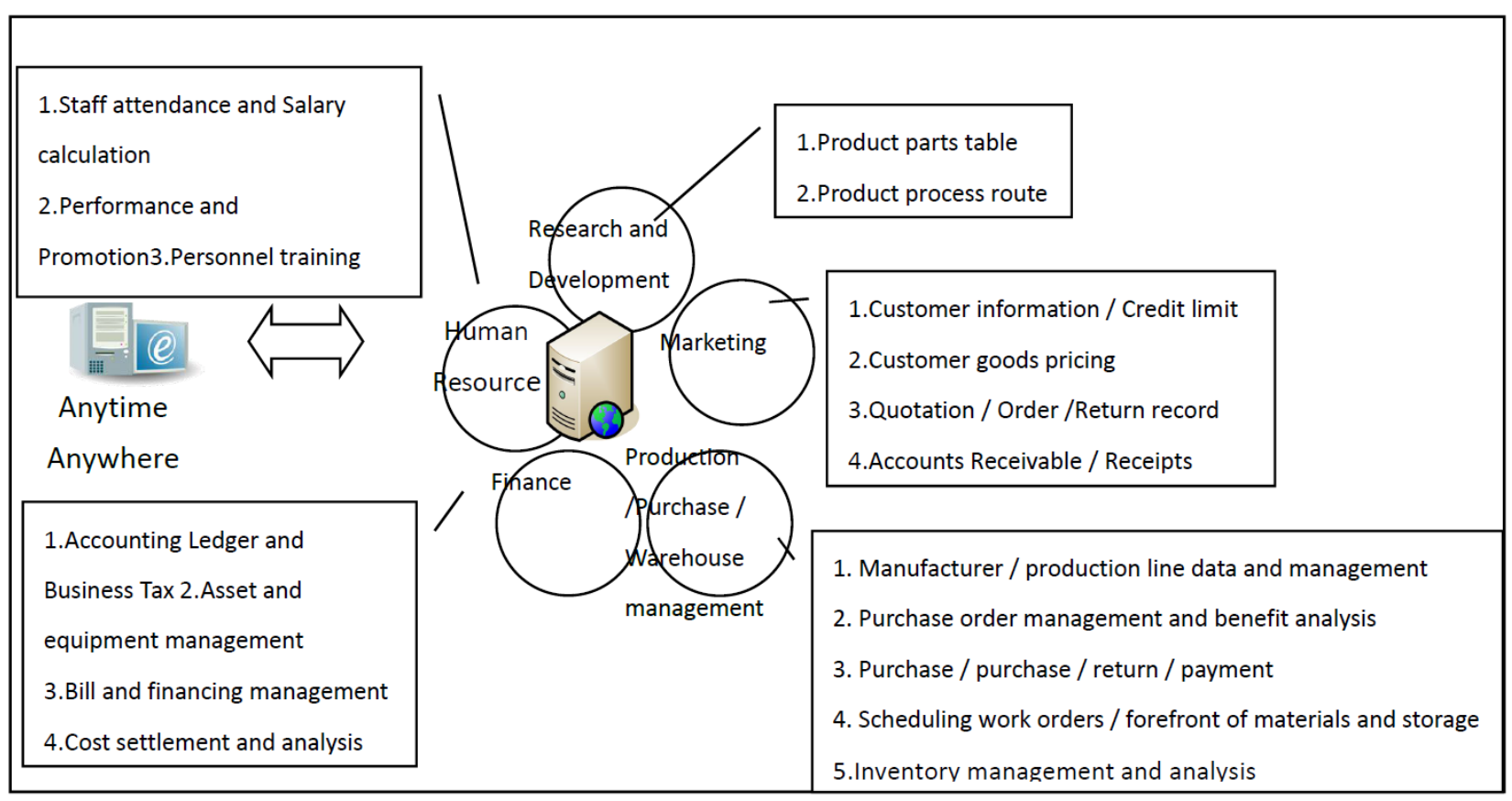

FIGURE I. "ENTREPRENEUR PHILOSOPHY" SIMULATED ENTERPRISE MANAGEMENT FUNCTION SYSTEM

Second, the business process of this model is basically compatible with the mainstream ERP management software process (for example, "Order Change Audit", see Figure II), To a certain extent, it overcomes the defects of the traditional enterprise simulation sand table which only make decision and become a "game".

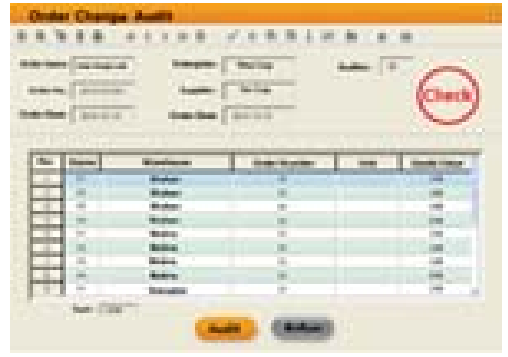

FIGURE II. "ENTREPRENEUR PHILOSOPHY" SIMULATED ORDER CHANGE REVIEW SHEET

Third, information interconnection breaks isolation and creates diversity of information interconnection.The application of "Entrepreneur Philosophy" is based on the environment of WAN,as shown in Figure III.

In addition, "Entrepreneur Philosophy" can be accessed on local clients such as computers, mobile phones, and tablets, overcoming the disadvantage of isolated communication.

\section{CONCLUSION}

Currently, the mainstream business operation simulation sandboxes in China are based on business competition philosophies of the 1970s and 1980s, more and more limitations of thought and technology are revealed. To solve the said problems, we preliminarily explore the establishment of an "operation simulation system for technological innovation-based manufacturing enterprises".

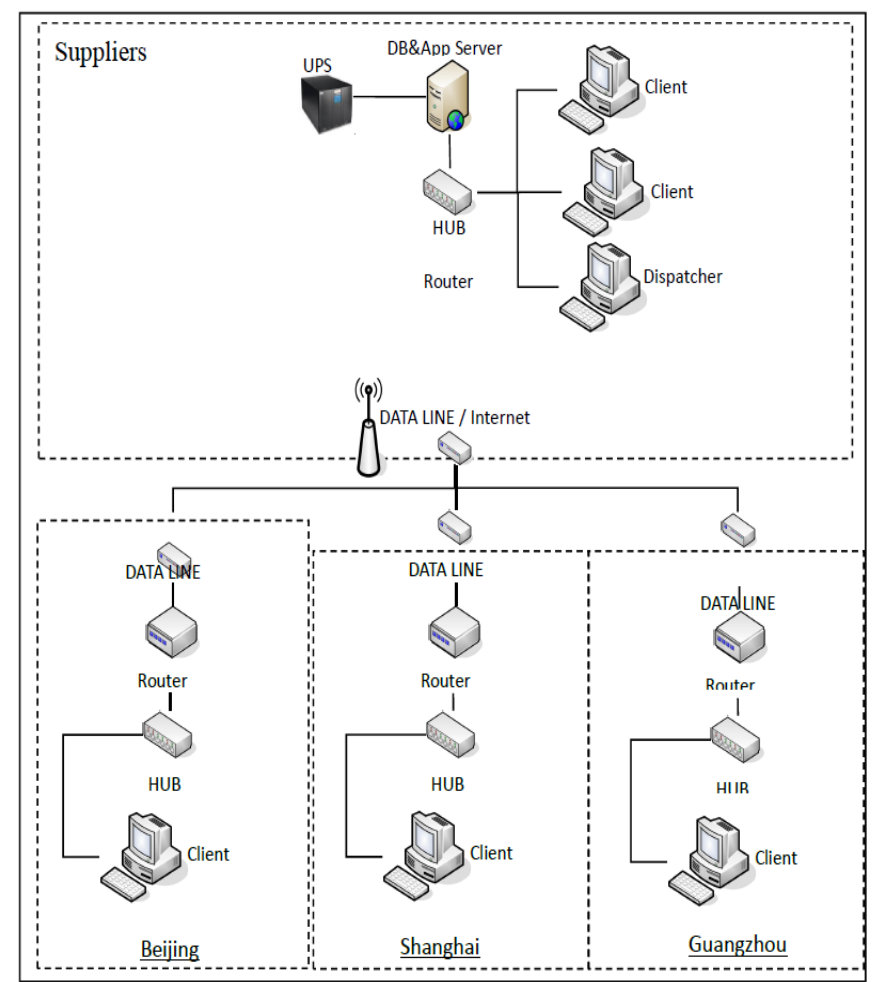

FIGURE III. "ENTREPRENEUR PHILOSOPHY" WAN DEPLOYMENT Railway publishing house, 2014.9.

\section{REFERENCES}

[1] Shijun Tang.Discussion on the development and innovation of the "Second Class" of ERP talents training [J].Contemporary Economic, 2013(7)

[2] LinYan , Shijun Tang.SCM Simulation Course [M].China Railway Publishing House, 2014.9. 